\title{
UMA REVISÃO BIBLIOGRÁFICA E PESQUISA SOBRE LIVROS DIDÁTICOS DE MATEMÁTICA, TECNOLOGIA E ENSINO DE GEOMETRIA NO ENSINO FUNDAMENTAL E MÉDIO
}

\section{A BIBLIOGRAPHIC REVIEW AND RESEARCH ON DIDACTIC BOOKS OF MATHEMATICS, TECHNOLOGY AND TEACHING OF GEOMETRY IN FUNDAMENT AL AND AVERAGE EDUCATION}

\author{
Geane de Oliveira Romano \\ Universidade Cruzeiro do Sul, geane.gor@gmail.com \\ Juliano Schimiguel \\ Universidade Cruzeiro do Sul, schimiguel@gmail.com
}

\author{
Marcelo Eloy Fernandes \\ Universidade Cruzeiro do Sul, marceloeloyfernandes@gmail.com
}

\section{Resumo}

É notória a importância e necessidade da utilização das novas tecnologias no decorrer do processo educativo, em atendimento as reais necessidades e demandas do atual contexto. Deste modo, torna-se igualmente imprescindível a articulação das novas tecnologias no ensino de geometria com os livros didáticos de matemática distribuídos às escolas pelo Programa Nacional do Livro Didático (PNLD), recurso principal na prática do ensino atual em consonância com "imigrantes e nativos digitais". A utilização de novas estratégias e recursos didáticos se faz necessária numa perspectiva de motivação e inovação para o processo de ensino e aprendizagem. O presente artigo teve por objetivo realizar uma revisão sistemática bibliográfica em periódicos e artigos qualificados acerca da articulação dos livros didáticos de matemática do PNLD, o quesito tecnológico e diretrizes no ensino da geometria. Os resultados apontam que há um forte movimento de mudança e adaptação dos conteúdos matemáticos, em especial o geométrico, nos dias atuais por conta da tecnologia.

Palavras-chave: Tecnologia, Geometria, Livros Didáticos, Matemática

\section{Abstract}

The importance and necessity of the use of new technologies in the course of the educational process, in response to the real needs and demands of the current context, is 
well known. Thus, it is also essential to articulate the new technologies in geometry teaching with the textbooks of mathematics distributed to schools by the National Textbook Program (PNLD), a key resource in current teaching practice in line with "immigrants and natives digital ". The use of new strategies and didactic resources is necessary in a perspective of motivation and innovation for the teaching and learning process. The aim of this article was to carry out a systematic bibliographical review in periodicals and qualified articles about the articulation of the mathematical textbooks of the PNLD, the technological question and guidelines in the teaching of geometry. The results indicate that there is a strong movement of change and adaptation of the mathematical contents, especially the geometric, in the present day due to technology.

Keywords: Technology, Geometry, Textbooks, Mathematics

\section{Introdução}

$\mathrm{Na}$ educação formal, no ensino-aprendizagem de matemática nos níveis fundamental e médio, a utilização dos livros didáticos é uma prática frequente entre professores - e, muitas vezes, a única fonte de pesquisa -, muito embora dever-se-ia levar em conta outras maneiras, diretrizes e métodos de transmissão de conhecimento, assim como a possibilidade de adentrar em outros ambientes, como o digital.

Diante do novo perfil dos alunos, os conhecidos "nativos digitais", percebe-se a destreza e pré-disposição dessa nova geração. Estratégias no campo educacional que se adequem a esse público se faz importante, visto que o ambiente digital propaga informações instantaneamente, bem como estreita a relação entre professor e aluno em sua comunicação e interação, seja através de chats online, transferência de arquivos ou até mesmo e-mails. Os nativos digitais vivem, naturalmente e diariamente, em uma cibercultura, na qual também se inserem indivíduos de outras gerações, que estão cursando níveis superiores, pós-graduações, mestrados e doutorados - sendo estes últimos considerados por Prensky (2001), criador de ambos esses termos, como "imigrantes digitais". Para o autor, todos aqueles que não nasceram na "Era Digital", mas que, de alguma forma, convivem e adotam essa tecnologia em seu cotidiano serão sempre comparados aos nativos digitais, mas não poderão ser considerados desta maneira. 
O objetivo geral deste artigo é realizar uma revisão sistemática bibliográfica em periódicos e artigos qualificados acerca da articulação dos livros didáticos de matemática do PNLD, o quesito tecnológico, diretrizes pedagógicas no ensino da geometria.

A escolha do tema ocorreu em função de vivências e experiências adquiridas ao lecionar a disciplina de matemática e atuar como coordenadora pedagógica na educação formal e não formal.

\section{A Evolução dos livros didáticos e o conteúdo geométrico}

Percebe-se que as mudanças no trajeto da educação, e mais especificamente no ensino da geometria, é atemporal. Um estudo, realizado por Santos e Alves (2018), discutiu sobre a trajetória curricular da matemática, com a inserção da Geometria em 1841, no Pará. Os autores concluíram que o contexto histórico e a formação dos Presidentes da Província do Grão-Pará (em matemática e/ou áreas semelhantes) influenciaram na educação e no trajeto curricular da matemática desse local que, por sua vez, poderiam influenciar no restante do Brasil, tanto na questão da infraestrutura (na qual obras públicas eram construídas por estes "mestres em geometria prática", como eram denominados), mas principalmente em relação aos conceitos que eram trazidos da Europa e disseminados em todo o país no âmbito escolar.

No Brasil, o livro didático passou a ser difundido em 1929, após a criação do Instituto Nacional do Livro (INL), que o legitimou e auxiliou em sua produção em massa. Em 1938, fora criado um decreto que fiscalizaria o livro didático - momento histórico, no qual o governo passou a controlar o material e as informações que seriam desenvolvidas no âmbito escolar (DASSIE, 2008).

Entretanto, foi somente após a extinção da Fundação de Assistência ao Estudante (FAE) e a transferência do Programa Nacional do Livro Didático (PNLD) para o Fundo Nacional de Desenvolvimento de Educação (FNDE) que os livros foram produzidos e distribuídos em massa e continuamente (MENDONÇA, 2016). Além da PNLD, hoje temos o Programa Nacional do Livro Didático para o Ensino Médio (PNLEM) e o Programa Nacional do Livro Didático para Alfabetização de Jovens e Adultos (PNLA), que foram criados em 2004 e 2007, respectivamente, pelo governo federal. Desde sempre, livros didáticos trazem uma certa ambiguidade sobre quem é, de fato, seu consumidor direto: o aluno ou o professor. 
Bittencourt (2004) explica que, a priori, era o professor o maior consumidor de livros didáticos, embora a partir da segunda metade do século XIX, o público também passou a ser o aluno e, para isso, os mais diversos autores deste tipo de livro tiveram que inovar e adaptar suas obras ao novo público-alvo, inserindo, inclusive, novos gêneros didáticos.

Por várias décadas, o livro didático foi um material de extrema importância, sendo um sustentáculo ao docente e ao discente, embora Bittencourt (2004) e Prensky (2001) acreditam que este não deva ser, no mundo contemporâneo, a única fonte de pesquisa de ambos, afinal, seu conteúdo não é imutável.

Acreditar na imutabilidade do conteúdo do livro didático é limitar o indivíduo a um único meio de aprendizado, removendo-lhe o benefício de optar por novas formas de satisfazer sua sede de conhecimento. Nesse sentido, o livro didático deverá se solidificar como uma ferramenta de conhecimento humano, subdividido em disciplinas e conteúdos, mas que deve ser tratado de forma alternativa, e não predominante, principalmente em salas de aula. Mesmo na chamada Era da Informação, o livro didático acaba sendo, muitas vezes, a única fonte de consulta dos docentes e discentes, embora ambos tenham acesso ao conteúdo tecnológico - o que é curioso, pelo fato de que, historicamente, adotamos critérios cada vez mais rígidos para a escolha do livro didático que será apresentado e trabalhado nas escolas. Atualmente, o mesmo critério vem se mostrando inadequado, afinal de contas, há metodologias que se mostram muito mais eficazes do que esta última, como é o caso da tecnologia.

Adentrando mais acerca do conteúdo geométrico nos livros didáticos, no Brasil, sua aprendizagem esteve em segundo plano por muito tempo. Os motivos, para Lorenzato (1995), é de que docentes não possuíam o conhecimento basilar para ensinar esse conteúdo, e que livros didáticos, na época, traziam apenas um conjunto de fórmulas que eram trabalhados apenas em seus capítulos finais - que, na maioria das vezes, não eram estudados junto aos alunos por falta de tempo. Pavanello (1993) complementa explicando que, no caso dos docentes, a geometria era trabalhada como "um complemento" no currículo do curso.

Além de todos esses fatores citados anteriormente, havia também a Lei 5.962/71, na qual permitiu o próprio docente organizar sua programação e, por se sentirem 
inseguros com seu próprio conhecimento em trabalhar com a matéria, optava-se por não a ingressar no roteiro de aulas (BRASIL, 1971).

Homologada em dezembro de 2017 pelo MEC (Ministério da Educação), a Base Nacional Comum Curricular (BNCC) enfrenta o problema enfrentados pelos discentes na modernidade, o que reflete nos indicadores de qualidade da educação brasileira: a falta de oportunidades para o ingresso, permanência e aprendizado escolar; um organizado patamar educacional, que desenvolve e acolhe $O$ aluno em sua diversidade e conjuntura; e a busca pela equidade e igualdade. A BCNN, que foi criada à luz dos Parâmetros Curriculares Nacionais (PCN) e das Diretrizes Curriculares Nacionais (DCN) indica as competências na qual os alunos deverão desenvolver, flexibilizando os sistemas de ensino a adequarem seus currículos, tendo como referência a Base, levando em consideração as necessidade e possibilidades dos estudantes de determinada localização. Isto permite aos sistemas de ensino planejar anualmente o seu trabalho, rotina e eventos, além de fortalecer o regime colaborativo entre as esferas governamentais.

A Base Nacional Comum Curricular, no Ensino Médio do $1^{\circ}$ ao $3^{\circ}$ ano, possui um diferencial com relação ao Ensino Fundamental haja vista o quesito tecnológico estar explícito quanto as habilidades de matemática e suas competências na área de conhecimento Matemática. É possível verificar que a BNCC apresenta propostas para a utilização das novas tecnologias e fazem referência a softwares, aplicativos de álgebra e geometria dinâmica como recursos complementares, para o desenvolvimento de habilidades no conteúdo de geometria como por exemplo: apoio de tecnologias digitais como, por exemplo, softwares, aplicativos de álgebra e geometria dinâmica

Até o ano passado, a Geometria era trabalhada em dois dos quatro blocos de conteúdos de ensino matemático, apresentados nos Parâmetros Curriculares Nacionais (PCN) de $1^{\circ}$ ao $5^{\circ}$ ano de ensino, e do $6^{\circ}$ ao $9^{\circ}$ ano de ensino. Neste primeiro bloco, chamado de "Espaço e Forma", os livros didáticos buscam explorar esses dois conteúdos introdutoriamente, bem como características de figuras tridimensionais e bidimensionais. O segundo bloco, denominado "Grandezas e Medidas", buscam proporcionar maior compreensão destes conteúdos.

Por fim, nos anos finais, os livros didáticos trabalham com a continuação dessas aprendizagens anteriores, propondo exercícios de construções geométricas - alguns, 
inclusive, sugestionando o uso de tecnologias digitais para melhor compreensão e entendimento das propriedades das figuras, bem como expansão do conhecimento nessa área. Para Pachêco et al. (2017), a geometria era intuitiva, depois, científica e, nos dias de hoje, pode ser considerada demonstrativa.

\section{Os Nativos digitais, os imigrantes digitais, a aculturação e o etnocentrismo}

Criado por Prensky (2001), o termo nativo digital se refere a todas as crianças, jovens e adolescentes que desde cedo manuseiam e utilizam corriqueiramente dispositivos tecnológicos, como celulares smartphones, tablets, computadores, entre outros e que the permitem viver uma vida online e offline todos os dias. Já aqueles que iniciaram o acesso tardiamente, na fase adulta, mesmo que também tenham acesso e fácil manuseio com estes dispositivos tecnológicos, são denominados imigrantes digitais.

A diferença central entre estes dois termos, para Moran (2011) e Kenski (1998), está na capacidade que a geração moderna tem em acessar estes meios, sendo que para outras gerações o acesso era limitado, não havia meios universalizados de troca de informações, como mensagens instantâneas. Para os nativos digitais tem-se uma grande gama de ambientes de troca de informações e espaços apropriados para pesquisar, interagir e se desenvolver, tudo em poucos cliques.

Segundo Franco (2013), os nativos digitais, tendo facilidade e estando conectados aos ciberespaços, manuseiam computadores, games e vídeo games, e esta conexão, por meio das redes sociais, possibilita os relacionamentos sociais haja vista compartilharem suas opiniões, ideias, fotos, vídeos, mensagens com pessoas que integram seu cotidiano e convívio, bem como pessoas com que mantém contato apenas virtualmente. Os nativos digitais ocupam-se com várias tarefas ao mesmo e realizam pesquisas com muita agilidade.

Trata-se de uma geração que, basicamente, nasceu com a habilidade de manusear equipamentos eletrônicos e, nesse sentido, novas tecnologias mais fáceis associadas por esse público.

Prensky (2001) ressalta que este tipo de domínio traz mudanças inclusive no processo cognitivo do indivíduo pelo fato destes assimilarem jogos e estarem habituados com aplicativos que requerem raciocínio rápido, como velocidade, destreza e tempo de 
execução de toques (em smartphones e tablets) ou cliques (em computadores). No ambiente escolar, no entanto, há um cenário de incomunicabilidade entre nativos e imigrantes digitais. Trata-se de um choque de culturas, ou, para Sam e Berry (2006), a aculturação. A aculturação, segundo o autor, não percorre somente escolas, mas empresas em todo o mundo, e ela é caracterizada por mudanças no ambiente diante de culturas distintas que refletem a individualidade e a geração dos indivíduos que ali estanciam.

Nestes casos, para Hazijadeh (2009), o primeiro passo é uma intermediação entre a "cultura original e a anfitriã", identificando quais os melhores aspectos de cada uma delas e implementando-as no ambiente de convivência (DEARDORFF, 2009).

Por um lado, nativos digitais (alunos) não acreditam que a aula possui sentido prático, ausência de didática por falta do docente, estrutura inapropriada, ausência e/ou falta de acesso de recursos didáticos tecnológicos. Por parte dos imigrantes digitais (professores), os nativos são indisciplinados, apáticos e desinteressados pelo ambiente escolar, em geral (CARRANO, 2008).

Prensky (2001) acredita que os imigrantes estão tentando ensinar nativos, que, por si só, expressam e entendem uma forma de linguagem totalmente diferente deles. Eles preferem gráficos ao invés de textos, são resistentes e debatem sobre cada afirmação feita pelo professor, absorvem informações de múltiplas fontes e desprezam processos lineares de informação (DEMO, 2002; OBERG, 2006).

Rosinski (2003) acredita que a aculturação é comum no mundo, mas que o Brasil, assim como os Estados Unidos, tem uma característica etnocêntrica, isto é, uma visão que considera um determinado grupo mais importante que os outros - o que influencia diretamente na educação do país. Para Kumar (2000), o etnocentrismo intrinca na conexão entre indivíduos de gerações diferentes, ocasionando na ausência da empatia. Apesar disso, há maneiras de minimizar seus efeitos e consequências e, para isso, deverá haver estímulos entre os participantes, a fim de que os trabalhos sejam otimizados. Para nativos, deve-se prepara-los para a adaptação dos meios de comunicação direta com seus professores. Para imigrantes digital, uma formação Construcionista a fim de que compreendam novas formas de trabalho, comunicação e dinamismo ao transmitir conteúdos no ambiente escolar. Os dispositivos tecnológicos, 
mais do que facilitadores, tornaram-se ferramentas pedagógicas obrigatórias a fim de atender as necessidades dos alunos (PRENSKY, 2001).

\section{O ensino da Geometria por Meio da Tecnologia}

Há um consenso entre os aportes teóricos de que as escolas precisam valorizar e incentivar o bom uso das tecnologias em sala de aula, viabilizando que os nativos digitais façam a interação com esses recursos a fim de desenvolver e ampliar o processo educativo. Para Rossini (2010), a partir do desenvolvimento de cada vez mais tecnologias:

[...] têm-se grande variedade de meios, e recursos que frequentemente, auxiliam os docentes em seu trabalho didático. Porém, para que o processo de ensino e aprendizagem se realize de forma satisfatória, usando-se as tecnologias de informação, é necessário que o software utilizado seja educativo, e que o professor tenha capacitação suficiente para utilizar o computador como meio educacional (ROSSINI, 2010).

A pesquisa de Frantz e Dalcin (2017), se baseia na utilização de máquinas fotográficas para ampliar o conhecimento matemático, em específico a geometria. Os autores acreditam que é possível ensinar e aprender conteúdos matemáticos através de atividades que utilizam a fotografia como recurso didático, embora assim como Prensky (2011), Oberg (2006) e Demo (2002), compreendem que o grande desafio é formar professores que estejam conectado com as novas tecnologias e metodologias de ensino para o uso destas, fazendo com que seja possível potencializar o aprendizado dos seus alunos. Dentre as conclusões de seu estudo, os autores evidenciaram que as imagens fotográficas favorecem a uma melhor compreensão da realidade vivenciada pelos estudantes, auxiliando no "pensar-matematicamente", que dependem de cálculos, como tempo de exposição, profundida, proporção, distâncias, estimativas, perspectivas, enquadramento, entre outros.

Já a pesquisa de Vieira e Escher (2018) apresenta Softwares Educacionais para a Geometria que poderiam ser utilizados dentro do ambiente escolar, dentre eles o Cabri e Cinderella, que são softwares de construção com o uso de réguas e compassos eletrônicos; iGeom, que permite construir figuras geométricas e interagir com elas; Poly, que trabalha com sólidos tridimensionais em sua forma planificada e vista topológica; Régua e Compasso, que permite realizar simulações com as formas geométricas criadas e; Geogebra, que reúne a geometria, álgebra e cálculos gerais, podendo construir 
vetores, equações, poliedros, realizar estudo do círculo (circunferência, raio, diâmetro e área), dentre várias outras possibilidades.

Analisando a literatura especializada da área não é fácil notar expressivos esforços na busca por sanar a problemática específica da necessidade de articulação do quesito tecnológico nos livros didáticos de matemática, na matéria de geometria. Nesse sentido, é possível analisar as publicações da Revista de Ensino de Ciências e Matemática (REnCiMa) que tratam acerca do assunto.

As publicações encerradas em tal revista apontam de forma enfática a necessidade existente de articulação entre tecnologia e docência, haja vista as condições socioculturais atualmente presenciadas.

Ainda assim, conforme exposto por Giraffa (2010), tal articulação ainda está muito aquém da necessária, seja devido às políticas públicas ou à formação não efetiva dos professores no campo da cibercultura. Desse modo, a autora chama a atenção à necessidade do professor de se envolver nas novas condições socioculturais que formam 0 aluno.

Uma série de outros trabalhos aparentam registrar esforços dessa prática, que leva em conta o quesito tecnológico no ensino de matemática. Dentre eles, é possível ressaltar os estudos de Viana e Boiago (2015), bem como os trabalhos de Oliveira et al. (2011) e Pereira e Guerra (2016).

Tais estudos chamam a atenção devido a seu caráter aplicado na prática docente, no que se refere ao uso de aplicativos próprios ao âmbito geométrico no ensino dessa matéria.

Como resultado dos trabalhos de Pereira e Guerra (2016, p. 70), os autores concluem que: "verificou-se que os Applets criados no GeoGebra, em geral, facilitam a compreensão de trigonometria, pois ao visualizar um objeto matemático movimentando na tela do computador e podendo manipular várias vezes o objeto em apenas uma aplicação, o estudante, nessa interação, faz perguntas, levanta conjecturas e testa hipóteses. Portanto, o estudo de Trigonometria pode ser apresentado com bons efeitos de aprendizagem".

Tais considerações atestam a importância do uso tecnológico no ensino dos conteúdos geométricos no contexto atual. Ainda assim, tais autores atuam de forma alheia aos livros didáticos, apresentando uma aparente dissociação inconsciente entre o livro didático e a tecnologia. 
Em referência ao estudo quanto aos livros didáticos de matemática, apenas duas publicações podem ser encontradas no portal: SANTOS et al. 2018 e SOARES, 2018. Tais publicações, no entanto, voltadas ao campo da estatística e da probabilidade, encerram em seus estudos problemáticas que não envolvem o quesito tecnológico, não evidenciando a forma como tal elemento é trabalhado nos materiais.

\section{Metodologia da pesquisa}

A metodologia empregada neste estudo foi a bibliográfica. Para isso, foram analisadas as obras e artigos e periódicos especializados no tema do trabalho.

Primeiramente, buscou levantar o contexto histórico dos livros didáticos e o conteúdo geométrico, sob contribuição das obras de Santos e Alves (2018), Oliveira e Mendonça (2016), Bittencourt (2004), Prensky (2001), Lorenzato (1995), Pavanello (1993), e Pachêco et al. (2017).

Em seguida, tratou-se dos conteúdos dos termos nativos digitais, imigrantes digitais, aculturação e etnocentrismo, na qual contribuíram as pesquisas do criador dos termos, Prensky (2001) e de Moran (2011), Kenski (1998), Franco (2013), Sam e Berry (2006), Hajizadeh (2009), Deardorff (2009), Carrano (2008), Demo (2002), Oberg (2006), Rosinski (2003) e Kumar (2000). Finalmente, tratou-se do ensino da geometria por meio da tecnologia, tendo como principais contribuições as obras Frantz e Dalcin (2017) e Vieira e Escher (2018).

\section{Considerações finais}

A presente investigação foi desenvolvida com o intuito realizar uma revisão sistemática bibliográfica em revistas e artigos acerca da evolução dos livros didáticos matemáticos no quesito tecnológico no ensino da geometria.

Para tanto, nos dedicamos a identificar a evolução dos livros didáticos e o conteúdo geométrico, avaliando as mudanças no trajeto da educação e no ensino da geometria, destacando a difusão do livro didático no Brasil, a extinção da Fundação de Assistência ao Estudante (FAE), a transferência do Programa Nacional do Livro Didático (PNLD) para o Fundo Nacional de Desenvolvimento de Educação (FNDE) e criação do Programa Nacional do Livro Didático para o Ensino Médio (PNLEM), assim como tratamos da 
ambiguidade do livro didático a respeito do seu público-alvo; da mutabilidade do conteúdo do livro; do ensino dos conteúdos geométricos (que por muitos anos ficou em segundo plano) que atualmente está contemplado no decorrer do ensino básico e teve mudanças sua forma de ensino-aprendizagem no ambiente escolar, haja vista as novas propostas que constam nas BNCCs por meio das novas tecnologia e que consequentemente deverão impactar na forma de apresentação e abordagem dos conteúdos nos livros didáticos, uma vez que as mesmas são diretrizes obrigatórias para a edição todo o material didático para o ensino básico seja na forma impressa ou digital.

Abordou-se os conceitos de nativos digitais, imigrantes digitais, aculturação e etnocentrismo. Foi percebido que os nativos devem ser preparados para a adaptação dos meios de comunicação direta com os professores, e que os professores, por sua vez, devem possui uma formação construcionista, a fim de não utilize o computador como uma reprodução de conhecimentos e modelos pedagógicos convencionais, mas como uma máquina a ser ensinada, onde o nativo possa construir sua própria percepção do uso da tecnologia.

Por fim, discorreu-se sobre o ensino da geometria através da tecnologia, no qual destacou-se as pesquisas de Frantz e Dalcin (2017), que ampliam o conhecimento matemático geométrico com a utilização de máquinas fotográficas, e a pesquisa de Vieira e Escher (2018), que apresentam diversos softwares educacionais geométricos como sugestão de uso em ambiente escolar.

Percebe-se que há um forte movimento de mudança e adaptação dos conteúdos matemáticos, em especial o geométrico, nos dias atuais. A história da matemática, a percepção da matemática como uma "estrutura organizada de forma lógica", a disposição dos capítulos nos livros didáticos do ensino do conteúdo geométrico, a intercalação do conteúdo geométrico com outros conteúdos matemáticos e a falta de interesse por parte dos nativos digitais diante da maneira como o conteúdo é aplicado são indícios de que ainda há muito o que se fazer para tornar a geometria um objeto de interesse mútuo entre professores e alunos.

Nas Bases Nacionais Comuns Curriculares, no ensino médio do $1^{\circ}$ ao $3^{\circ}$ ano, existe um diferencial com relação ao ensino fundamento nas competências e habilidades na área do conhecimento matemático e suas tecnologias. Verificou-se que existe uma proposta para a utilização das novas tecnologias como recurso complementar para o desenvolvimento de habilidades no conteúdo de geometria. 
A abordagem da geometria ocorre em todos os anos. Já nas Bases Nacionais Comuns Curriculares, para o ensino fundamental, consta a utilização de recursos tecnológicos desde o $5^{\circ}$ ano, e os conteúdos de geometria estão distribuídos em todos os anos.

A partir desta, conclui-se que, como os livros didáticos devem contemplar as bases nacionais comuns curriculares, conforme previsto no PNLD e PNLDEM, consequentemente, houve um avanço quanto a exigência de que os livros contemplem também o quesito tecnológico.

É preciso se adaptar às mudanças e, mais do que simplesmente aceitá-las, tirar proveito delas no ambiente educacional.

\section{Referências}

BITTENCOURT, Circe Maria Fernandes. Ensino de História: fundamentos e métodos. São Paulo: Cortez, 2004.

BRASIL. Senado Federal. Lei de Diretrizes e Bases da Educação Nacional: no 5.692/71. Brasília, 1971.

DASSIE, Bruno Alves. Euclides Roxo e a constituição da Educação Matemática no Brasil. 2008. 271 f. Tese (Doutorado em Educação) - Pontifícia Universidade Católica do Rio de Janeiro, Rio de Janeiro, 2008.

DEARDORFF, Darla K. The SAGE handbook of intercultural competence. California: SAGE Publications, Inc, 2009.

DEMO, Pedro. Complexidade e Aprendizagem: a dinâmica não linear do conhecimento. São Paulo: Atlas, 2002.

FRANTZ, Débora de Sales Fontoura da Silva; DALCIN, Andréia. Fotografia e Matemática em uma escola do campo: ampliando olhares, construindo saberes. REMATEC, ano 12, n. 25, mai/ago, 2017.

FRANCO, C. P. Understanding Digital Natives. Learning Experiences. Revista Brasileira de Linguística Aplicada, 13(3), 2013. 
GIRAFFA, L. M. M. Vamos bloggar professor? Possibilidades, desafios e requisitos para ensinar matemática no século xxi. REnCiMa, v. 1, n. 2, p. 97-110, jul/dez 2010.

HAJIZADEH, Neda. The Relationship Between Acculturation, Intergenerational Family Conflict, and Late Adolescent Psychological Adjustment in Asian Indian College Students. Pro Quest, 2009.

KENSKI, V. M. Novas Tecnologias: o redimensionamento do espaço e do tempo e os impactos no trabalho docente. Revista Brasileira de Educação, Brasília, n.8, 1998.

KUMAR, Margaret. Postcolonial Theory and Cross-culturalism: Collaborative 'Signposts' of Discursive Practices. Australia: University of South Australia. Journal of educational Enquiry, Vol.1, № 2, 2000.

LORENZATO, Sérgio. Porque não ensinar Geometria? Educação Matemática em Revista. v. 3, n. 4, 1995.

MENDONÇA, Thiago Neves. Que geometria ensinar às crianças em tempos de matemática moderna? Referências e práticas de uma professora da cidade de Juiz de Fora, Dissertação (mestrado), Programa de Pós-Graduação em Educação Matemática, Universidade Federal de Juiz de Fora, 2016.

MORAN, J. M. A Educação que Desejamos: novos desafios e como chegar lá. São Paulo: Papirus, 2011.

OBERG, Kalervo. Cultural Shock: Adjustment to New Cultural Environments. Reprint de 1960, Curare 29, 2006.

OLIVEIRA, F. K.; PONTES, M. G. O.; SANTANA, J. R.; CUNHA, R. B. O ensino de geometria por meio de múltiplas plataformas: uma experiência com o Geonext. REnCiMa, v. 2, n. 1, p. 30-49, jan/jun 2011.

PACHÊCO, Franklin Fernando Ferreira; PACHÊCO, Gisele Ferreira; SILVA, Anderson Douglas Pereira Rodrigues da. Uma análise em livros didáticos de matemática dos anos finais do ensino fundamental acerca da proposta do ensino de polígonos sob a ótica da teoria de Van Hiele. REVEMAT. Florianópolis, (SC), v.12, n. 2, 2017.

PAVANELLO, R. M. O abandono do ensino da Geometria no Brasil: causas e consequências. Zetetiké. v. 1, n. 1, p. 7-17, 1993. 
PEREIRA, E.; GUERRA, E. A. A utilização de applets no Geogebra para a aprendizagem da trigonometria no ensino médio. REnCiMa, v. 7, n.3, p. 53-72, 2016.

PRENSKY, Mark. Digital Natives, Digital Immigrants. In: On the Horizon. NCB University Press, n.5, v.9, 2001.

ROSINSKI, Philippe. Coaching Across Cultures. London: International Journal of Coaching in Organizations, 2003.

ROSSINI, M. A. P. Um estudo sobre o uso de régua, compasso e um Software de geometria dinâmica no ensino da Geometria hiperbólica. Dissertação (Mestrado em Educação Matemática) - Instituto de Geociências e Ciências Exatas, Universidade Estadual Paulista, Rio Claro, 2010.

SAM, David L.; BERRY, John W. The Cambridge Handbook of Acculturation Psychology. UK: Cambridge University Press, 2006.

SANTOS, Everaldo Roberto Monteiro dos Santos; ALVES, José Jerônimo de Alencar. Inovações matemáticas no ensino da província do Grão-Pará (1838-1841). REMATEC, ano 13, n. 27, jan/abr, 2018.

SANTOS, W. D.; SANTOS JR., J.; VELASQUE, L. S. O desenvolvimento do letramento estatístico pelos livros didáticos e a base nacional comum curricular. REnCiMa, v.9, n.2, p. 210-229, 2018.

SOARES, E. Uma análise sobre as atividades de probabilidade propostas em livros didáticos de matemática dos anos finais do ensino fundamental. REnCiMa, v. 9, n.6, p. $65,2018$.

SOUZA, Samuel Mercês; BORGES, Luzineide Miranda. As redes sociais virtuais, os nativos e imigrantes digitais. In: ENCONTRO NACIONAL SOBRE HIPERTEXTO, 3, Belo Horizonte. Anais... Belo Horizonte, 2009.

VIANA, O. A.; BOIAGO, C. E. P. Modelagem matemática no Geogebra: uma análise a partir dos registros de representação semiótica. REnCiMa, v. 6, n. 3, p. 23-37, 2015.

VIEIRA, Andréa Aparecida; ESCHER, Marco Antônio. Construções Geométricas Utilizando Régua e Compasso e Softwares Educacionais. Revista de Educação, Ciências e Matemática, v.8, n.1, jan/abr, 2018. 
VIGOTSKY, L.S. Pensamento e Linguagem. São Paulo: Martins Fontes, 1987. 